\title{
Struggling to Make Good: The Dilemmas of Fatherhood for Formerly Incarcerated African-American Men
}

\author{
Francis Prior and Steven Farough ${ }^{\mathrm{a}}$
}

aAssumption University, Worcester, MA, USA

\begin{abstract}
While some have argued that absent low socioeconomic status black fathers are to blame for urban crime and poverty, others have highlighted how mass incarceration disproportionately separates low socioeconomic status black fathers from their children. Less frequently heard and acknowledged in the public conversations about low socioeconomic status black fatherhood and mass incarceration are the voices of those same fathers who have been impacted by the system. How do formerly incarcerated black fathers view their role as fathers? Based on 30 interviews of formerly incarcerated black men recruited from a prisoner reentry organization in a large northeastern city in the United States, we found that interviewees talked about fatherhood in two different ways. On the one hand, our most common finding was that interviewees talked about fatherhood as a motivation for desistance from criminal activity. In this finding they connected provider roles and being present in the lives of their children with their planned desistance from crime. On the other hand, interviewees also mentioned fatherhood as a part of explanations for past criminal activity, in what we call strain narratives. In these stories, they typically mentioned their provider roles as fathers as part of the overall economic strain that they faced. Counter to the dominant cultural impression of low socioeconomic status black fathers as absent/uncaring, both the desistance and strain narratives demonstrated a considerable amount of concern with respect to their identities as fathers, and therefore as men. We argue for the significance of masculinity in explaining the fatherhood narratives of formerly incarcerated black men. In doing so, we build on previous qualitative work on low-income fathers, crime as doing gender, and desistance narratives in prisoner reentry.
\end{abstract}

JQCJC "Qualitative Criminology," (2022)

Vol. 11, Iss. 1, 34-64

ARTICLE HISTORY

Received 5/10/2021

Accepted 6/21/2021

\section{KEYWORDS}

Desistence narrative, AfricanAmerican, fatherhood,

incarceration

In this paper, we document the ways in which formerly incarcerated African American men discuss their criminal activity as it relates to fatherhood. Our research shows that even when engaged in crime or turning away from it, formerly incarcerated African

DOI: https://doi.org/10.21428/88de04a1.dcb1accd 
"Qualitative Criminology"

American men see fatherhood as a key motivating identity for their behavior, a vision that runs counter to the stereotype of the absent or uncaring low socioeconomic status (SES) father. Analyzing interview data from a sample of 30 African American fathers participating in a state run prisoner reentry program, we found that they discussed fatherhood in two major ways. The first and more common manner in which these men discussed fatherhood was as a part of their desistance narratives, i.e., their resolutions to avoid future criminal activity. These narratives were anchored in conceptions of fatherhood that put an emphasis on being present in the lives of their children. However we found a tension in the data with a second type of narrative, which we call strain narratives. Here, men offered explanations of previous criminal activity anchored in their conception of themselves as fathers as economic providers. These strain narratives had a zero sum character to them. Men felt that they would lose their families if they did not provide for them, but that their options for providing for their families via the formal labor market were limited. As a result, they would turn to criminal activity to provide for their family. However, they also recognized that in choosing income producing crime, that they were taking on great personal risk, even if they were able to fulfill the provider role in the short term, which they identified as a dilemma. Finally, we have also identified how the centrality of fatherhood in the desistence narratives demonstrates their concern for their children in a way that challenges the longstanding vision of African American fathers as not wanting to be with their children.

We combine criminological frameworks of desistance and strain with scholarship on masculinity and fatherhood to better explain the dilemmas of fatherhood faced by the men in this sample. In this paper we build on work by criminologists that have focused on gendered desistance narratives and work that has conceptualized doing crime as doing gender. The desistance narratives also help illuminate how fatherhood is not a static role taken on by men but is instead a social process in which formerly incarcerated men actively reflect upon their attempts to perform hegemonic masculinity, therefore doing gender.

\section{Literature}

\section{Provider Strain, Gender, and Crime}

In the absence of gainful employment opportunities, low SES fathers who engage in criminal activity in order to provide for their families present a classic case of strain theory. Without legitimate means, income producing criminal activity is a "innovative" way to accomplish the culturally valued goals of economically supporting one's family per hegemonic masculinity (Merton, 1968). Agnew's general strain theory highlights that the failure to come to terms with cultural expectations rather than goals is salient (Agnew, 
1992). Agnew's general strain theory also points us towards a number of the different adverse emotional and social conditions that are likely pertinent to explaining their criminal activity, e.g., stress, negative emotions like anger, romantic conflict, mental health issues, etc. (Agnew, 1992, p. 58). Importantly, to the extent that low SES fathers explain their criminal activity in terms of the provider roles of fatherhood, i.e., a gendered cultural expectation that creates strain, their explanations rely on a hegemonically masculine (Connell \& Messerschmidt, 2005) conception of fatherhood. Insofar as their crime is explained or justified by this hegemonically masculine conception of fatherhood, it is an activity that can be analyzed as doing gender (Broidy \& Agnew, 1997; Miller, 1998; Messerschmidt, 2018; West \& Zimmerman, 1987). In this way, committing crime is not simply about resolving economic deprivation, but wrapped up with gender concepts like masculinity where men are expected to be economic providers. It also infers that there is a relationship between masculinity and economic power.

Feminist scholarship has been more explicit by theorizing masculinity as a social construction and generally a position of privilege and power (Connell, 1987; Kimmel, 2011). In addition, feminist scholarship on masculinity argues that we should conceive of masculinity as plural, where there are dominant or hegemonic conceptions of masculinity in relation to other forms of less powerful masculinity. In marginalized masculinity, men harbor much of the privileges of masculinity but not in terms of race or class advantages (Connell, 2005; Connell \& Messerschmidt, 2005). It is the dynamic between marginalized and hegemonic masculinity that is particularly important in the scholarship on fatherhood and crime. Similar to strain theorists, Messerschmidt (2018) argues that criminal activity by men is also an avenue to establish a particular style of marginalized masculinity when typical economic and social pathways are blocked or too challenging. When men lack access to normative pathways to income and status, they may turn to crime as a particular expression of masculinity. The different forms of masculinity illuminate how gender operates as a social structure-it is performed by individuals (usually male) at the micro level and simultaneously reproduced in broader patterns of gender.

Black masculinity in particular is the subject of a great deal of discussion beyond the contours of sociology and criminology (hooks, 2003; Majors \& Billson, 1993; McDougal III, 2020; Neal, 2015). Black studies scholars generally point to the fact that society in general is well aware of the more stereotyped aspects of black masculinitybroadly they trace out its historical and political origins as well as its contemporary commodification in the context of pop culture. Sociologists tend to examine black masculinity in particular social contexts. For instance, building on work that explains street crime as stemming from honor-culture practices, Stuart and Benezra find that rather than the aggressive hypermasculine code of the street (Anderson, 2000), that young black 
men in Chicago frequently adopt specifically non-threatening behaviors in public to reduce the likelihood of being targeted for stops by law enforcement (2018).

Sociologists regard the family as the primary institution of interest, with fatherhood roles as a direct connection to the gender concept of masculinity, and black masculinity specifically (Furstenberg, 2007; Hamer, 2001; Randles, 2020; Roy \& Dyson, 2010). Hamer extensively discusses the history of black male "live away" parenting and its connection to the history of racial oppression, i.e., slavery, Jim Crow, and economic disadvantage (Blauner, 2001; Coates, 2014) in the United States, in a way that undercuts the conception of the "live away" black father as fully "absent." Studies like Hamer's tend to show a range of involvement for black non-custodial fathers, from routinely involved, to somewhat involved, to completely absent, a range of involvement that is obscured by popular stereotypes of black fathers as absent or even "deadbeat" (Haney, 2018; Jarrett et al., 2002; Roy, 2006). Hamer's work, among others, helps show the ways in which the "live away" father is an adaptation to a white supremacist society that constrains the life chances of black fathers and their ability to provide economically while actively denigrating them culturally and symbolically by making the black father and the "good" father mutually exclusive. Moreover, psychological research has shown black fathers, custodial and non-custodial, suffer from "provider strain," are aware of the stereotypes about them, and utilize unique social and cultural resources as coping mechanisms in their attempts to do fatherhood (Bowman, 1990; Cooper et al., 2020, 2021; Griffith \& Cornish, 2018).

\section{The Political Economy of Fatherhood for Poor Urban Men}

Urban low SES fathers, particularly black low SES fathers, are the subject of a great deal of scholarship, with Nelson and Coley providing useful reviews on the subject from psychological and sociological perspectives respectively (Coley, 2001; Nelson, 2004). Popular conceptions of low SES fathers often rest on some version of either an oppositional culture (Gibson \& Ogbu, 1991; Majors \& Billson, 1993) or culture of poverty argument (Labor, 1981; Lewis, 1975; Mead, 1993) in which low SES fathers have children by different women as a testament to their hypermasculinity, alongside other socially maladaptive behaviors including drug use, criminal activity, and violence, and then subsequently fail to either support those children or be present in their lives. This vision of low SES fathers fits into the popularly understood social problem of the "deadbeat dad,"

and it has been the cause of a great deal of moral panic and policy deliberation that in the United States, including the creation of a formal child support apparatus connected to family court (Chambers, 1979). Scholars have pointed out the racialized nature of these culture of poverty tropes, in that low SES non-custodial fathers are typically envisioned as black men (Collins, 2005, 2008; Randles, 2020; Ryan, 1976). 
Moreover, immediately following the release of the Moynihan report, sociologists made numerous inquiries into fatherhood that provided more nuanced understandings of fatherhood among low SES urban men, black men in particular, that helped to reject a deficit oriented culture of poverty explanation of non-custodial fatherhood, including qualitative sociological work conducted in the 1960s (Liebow, 1967; Rainwater, 1967; Stack, 1997) and in the 1980s, 1990s, and 2000s (Anderson, 1992, 2000; Edin et al., 2004; Edin \& Nelson, 2013; Jarrett et al., 2002; Roy, 2006; Waller, 2002), as well as the important work of William Julius Wilson that focuses on the structural-economic conditions faced by urban low SES black fathers in particular (Wilson, 1990, 1997). This literature shows that while all low SES fathers face some difficulties in meeting the provider role expectations of modern versions of fatherhood due to low levels of educational attainment (Mincy et al., 2014), that low SES black fathers' difficulties performing fatherhood are also structured by an absence of stable low wage work in the urban core. This absence of work has caused high rates of joblessness, joblessness that tends to result in what scholars have called family disruption (Sampson, 1987). Moreover, black fathers' neighborhood level ecological conditions diverge from their white counterparts, including higher neighborhood level rates of crime and more recently the presence of the drug trade, both of which are due in part to racialized residential segregation (Massey \& Denton, 1993; Quillian, 2012).

The current study of formerly incarcerated black fathers builds upon the findings and insights of the aforementioned literature. While formerly incarcerated black fathers are a particularly disadvantaged subset within the larger category of low SES urban fathers, they are not a wholly distinct group, particularly when studies focus on chronically underemployed men who due to their felony convictions (Pager, 2009) end up relegated to informal secondary labor market (Venkatesh, 2009). Indeed many of the above studies as well as other more recent studies that do not select for incarcerated fathers in particular (Black \& Keyes, 2020; Randles, 2020) make note of the high rates of incarceration in their samples. Nevertheless, there are other studies like the current one, that are oriented towards the study of the impact of the criminal justice system on society more generally, that also select for men who are formerly incarcerated or are incarcerated at the time of the study, with samples that tend to overrepresent men of color, black men in particular (Curtis, 2019; Dyer, 2005; Haney, 2018; Jones, 2018; Lewis \& Hong, 2020; Jr. Lewis et al., 2007; McKay et al., 2019; Western, 2018).

Scholars have noted the ways in which low SES black fathers' relationships to their children are heavily mediated by and structured by the social institutions of state, e.g., prison, jail, probation, parole, child support, welfare offices, etc., as well as market, e.g., formal low wage employment, off-the-books employment that consists of legal behavior, and finally income producing criminal activity like selling narcotics or committing robbery, 
with criminal activity typically being a last resort due to the risks it imposes (Jarrett et al., 2002; Randles, 2020; Roy, 1999). Formerly incarcerated men face numerous barriers relevant to the fulfilment of the provider role, one of which is a decrease in lifetime earnings (Holzer, 2009; Western, 2002). In Homeward, Western's monograph that relies on interview data from the Boston Reentry Study, he shows how younger men of color leaving prison typically struggle to earn an income compared to their older white counterparts (2018, pp. 167-173). Haney's work artfully details the connection between court ordered child support payments and the criminal justice system-the standard sequence being as follows: 1) an employed custodial father is separated from his child via incarceration, 2) the mother of the child starts receiving public assistance (TANF) which triggers a public child support order for the father to defray the costs of public assistance, 3) the father, who is incarcerated, cannot earn money to support his children, but the debt of monthly payments still accumulates with interest, and 4) upon release, the father must begin paying a substantial amount of child support debt (on average about $\$ 10,000$ ), which is often quite difficult to get modified (Haney, 2018). Conditions like these are conducive towards pushing men towards low wage formal employment, where they will typically have their wages garnished, a dynamic which aggravates the social process of urban neoliberal debt peonage as described by Prior (2021). In general, it is very difficult for men to perform fatherhood while they are incarcerated, and incarceration tends to exacerbate the already existing issues present with low SES black fathers around earning income, being present in the lives of their children, and being able to care for them (Black \& Keyes, 2020; Curtis, 2019; Dyer, 2005; Haney, 2018; Lewis \& Hong, 2020).

\section{Desisting from Crime: Narrative and Intersectional Approaches}

Social scientists have conducted qualitative research on the role of desistance narratives among those who are at high risk for criminal activity, including those who are leaving prison and jail. For instance, analyzing longitudinal data from the Liverpool desistance study, Maruna found evidence that the men in this study tended to offer up "redemption scripts" which are a type of desistance narrative that explains both previous criminal activity and how individuals planned to avoid crime in the future (Maruna, 2001). Similarly, Giordano's analysis of delinquent youth in Toledo, Ohio, offered insight into how cognitive transformation was grounded in a social context which she and others describe as "hooks for change" as well as the ways in which processes like desistance are gendered (Giordano et al., 2002). This literature is relevant for understanding the ways in which desistance narratives are studied within qualitative criminology, such that we can understand better the specifics of how these patterns apply to the specific case of formerly incarcerated low SES black fathers. 
Scholars have noted the role of fatherhood in desistance narratives for systeminvolved fathers with samples that tend to overrepresent black fathers. In her book Dangerous Masculinity, Curtis finds that incarcerated low SES fathers typically do not believe they have much to offer with respect to fatherhood, and there are obvious issues of shame when it comes to parenting (2019). While Curtis notes the criminal justice system offers fatherhood classes to provide contact with their children on Christmas, she found some fathers opted not see their children, again due to shame. On the other hand, in Black and Keyes' exhaustive monograph It's a Setup containing 3 interview studies of low income fathers, about $40 \%$ of whom had experienced incarceration, they focus on, among other things, "fatherhood as a motivation to change" (2020, p. 183) which included narratives about desistance from criminal activity. In their substantial monograph based on interviews of 1,900 incarcerated men, McKay et al. similarly note the importance of parenting roles upon release for providing structure in men's lives reflecting earlier findings from Edin et. al. (Edin et al., 2004; McKay et al., 2019). In her ethnography The Chosen Ones, that focuses on the formerly incarcerated black men in the Bay area, Jones highlights the socially embedded nature of desistance narratives in a way that echoes Giordano's arguments, as her study participants are involved specifically in a project of "doing good" via their organization of support groups and involvement in crime prevention and not just the desire to "make good" (2018, p. 4). Jones also highlights the ways in which these desistance narratives and projects of "doing good" are simultaneously gendered and racialized (2018, p. 5). In particular, her in-depth interview work with key study participants highlights performing fatherhood as a behavioral turning point for formerly incarcerated men (2018, p. 55). Lewis and Hong conducted an interview study specifically upon formerly incarcerated black fathers in a fatherhood program where they examined fathers reflecting on their identities as fathers in which they explicitly utilize a "doing gender" framework that connects fatherhood identity to masculinity (2020). We similarly see the ways in which doing good is gendered and racialized with The Prison Journal's recent special issue that bridges the gap between Black Lives Matter activism and the prisoner reentry experience (Smiley, 2019; Williams, 2019; Williams et al., 2019). Much of this work is explicitly informed by an intersectional viewpoint that has become de-rigueur within feminist criminology (Burgess-Proctor, 2006; Chesney-Lind, 2006; Potter, 2015) and increasingly important for the qualitative prisoner reentry desistance literature (Fader \& Traylor, 2015).

\section{Data and Methods}

This current study is based on data collected for one author's doctoral dissertation, an ethnographic study of a prisoner reentry bureaucracy and its clients that was approved by a university IRB. The current study relies solely on interview data from this larger project. Prior conducted 57 digitally recorded semi-structured interviews of clients from a 
"Qualitative Criminology"

prisoner reentry organization referred to pseudonymously as "Afterward." Interviewees were selected based on their participation in Afterward's services. In order to take advantage of Afterward's prisoner reentry services, clients had to have a criminal record, but no active cases. Prior recruited interviewees by giving a 5 minute talk about the research project during their $\mathrm{CBT}$ and workforce development classes, where Prior also distributed consent forms. Interviews lasted about an hour, and were typically conducted at a nearby diner where Prior typically paid for lunch as a small incentive for participation in the study. Prior asked interviewees questions about their upbringing, family life, incarceration history, experiences with criminal justice supervision, experiences with Afterward's classes, and plans for finding employment and housing. Interviews were later transcribed.

In analyzing interview data, Prior followed grounded theory methodological procedures, which included going line by line and coding phrases using brief summary and analytical codes (Charmaz, 2014). Later Prior and Farough would recode this data in a more thematic fashion, driven by theoretical questions that emerged out of both Prior's participant observation experience and interview data. The authors used Atlas TI to facilitate the coding process. Both authors also wrote analytical and theoretical memos that acted as a bridge between interview transcripts and the analytical sections of this paper. Prior shared coded and de-identified interview transcripts with Farough to facilitate data analysis.

Table 1. Demographic characteristics of study population $(n=22)$

\begin{tabular}{lcrr}
\hline Characteristic & $\mathrm{n}(\%)$ & Characteristic & $\mathrm{n}(\%)$ \\
\hline Gender & & Age, years & \\
Male & $22(100.0)$ & $20-29$ & $7(31.8)$ \\
Race & & $30-39$ & $8(36.4)$ \\
Black & $22(100.0)$ & $40-49$ & $6(27.3)$ \\
& & $50-59$ & $1(4.5)$ \\
\hline
\end{tabular}

In addition to grounded theory coding, interviewees were tabulated by gender, race, age, conviction, work experience, level of education, number of children, housing, and incarceration history. The interview sample skewed black and male, with $80.7 \%$ of the sample being male, and $86 \%$ of the sample being black. Out of the 57 interviewees, 34 were fathers ( $-60 \%$ of the sample) and 30 were black fathers ( $\sim 53 \%$ of the sample). From this sample of 34 fathers, focused coding was conducted for evidence of codes related to research questions related to desistance narratives and strain narratives.

Out of those 34 interviewees, 22 of them provided evidence related to coding for desistance narratives and strain. All 22 of these interviewees were black men. Transcripts from these 22 interviewees were coded for 35 instances of fatherhood desistance 
narratives, 20 instances of fatherhood strain, 9 instances of fatherhood romantic conflict, and 8 instances of child support. Some interview excerpts were coded for multiple themes simultaneously, as they were illustrative of numerous sociological themes.

Table 2. Baseline characteristics of study population $(n=22)$

\begin{tabular}{lrrr}
\hline Characteristic & $\mathrm{n}(\%)$ & Characteristic & $\mathrm{n}(\%)$ \\
\hline Number of children & & Substantial work history & \\
1 & $6(27.3)$ & Yes & $8(36.4)$ \\
2 & $9(40.9)$ & No & $6(27.3)$ \\
3 & $5(22.7)$ & Borderline & $1(4.5)$ \\
4 & $1(4.5)$ & Unknown & $7(31.8)$ \\
5 & $1(4.5)$ & Work type & \\
Client housing & & Unskilled wage labor & $10(45.5)$ \\
Living with family & $13(59.1)$ & Skilled wage labor & $4(18.2)$ \\
Living w/ signif. other & $3(13.6)$ & Managerial work & $1(4.5)$ \\
Halfway house & $3(13.6)$ & Disability & $1(4.5)$ \\
Homeless shelter & $1(4.5)$ & Unknown & $6(27.3)$ \\
Unknown & $2(9.1)$ & Conviction* & \\
Education & & Violent & $14(63.6)$ \\
Less than high school & $4(18.2)$ & Drugs & $6(27.3)$ \\
GED or high school & $9(40.9)$ & Drugs and Property & $2(9.1)$ \\
Some college & $3(13.6)$ & Incarceration history & $16(72.7)$ \\
Unknown & $6(27.3)$ & Prison & $5(22.7)$ \\
& & Jail & $1(4.5)$ \\
\hline
\end{tabular}

Note: ‘`’ denotes conviction for most serious offense for clients with multiple convictions.

Tables 1 and 2 provide more detailed demographic and socioeconomic breakdown of the 22 interviewees. Interviewees were generally low SES. Fourteen out of 22 interviewees coded for desistance and strain narratives had experience with wage labor, with 10 interviewees having experience with unskilled wage labor and 4 with skilled wage labor. Eight had substantial work history, but 6 did not, and for 7 interviewees their experience was unclear from interview data. With respect to education, 3 had graduated high school, 6 interviewees had GEDs, 4 were high school dropouts, 3 had some college, and for 6 interviewees their level of education was unclear. Thirteen of the interviewees were living with family, though 3 were living with significant others, and 3 were living in halfway houses. 


\section{Analysis}

\section{Fatherhood and Desistance Narratives}

It was typical for interviewees to connect their identities as fathers to the desistance narratives that they presented. In a desistance narrative, we are given an account of how people will avoid criminal activity, which often includes employment. In interviews, Prior frequently asked interviewees what their plans were now that they were not incarcerated, particularly with respect to how they would make ends meet economically. When asked about their plans or their economic well being, interviewees would bring up their families unprompted as a motivating factor to seek out employment. An important part of hegemonically masculine fatherhood is the provider role. It was clear in the context of desistance narratives, that men viewed the income that they would earn from getting a job as crucial to the fulfilment of that role while simultaneously avoiding incarceration. For instance, Daniel, in his early thirties, responded like so:

Prior: You said you had a rough time. What did you mean by that?

Daniel: Rough time financially. As of right now. You know, I'm not working as of right now. I don't have an income. So, I have to come down and, you know, try to do something to better myself for me and my kids. You know, it's like, I really have no other option.

P: Tell me about your kids.

D: Well, I have three kids. I have a son, a thirteen year old. I have a two-year-old daughter. I have another four-year-old daughter.

Similarly, Gerald, in his early 40s, was asked about the kind of workforce development job he possessed prior to his conviction.

Prior: Do you think you'll be able to get into that [workforce development] industry again?

Gerald: I haven't tried, really. I haven't tried. Basically my thing's been trying to just put food on the table.

P: Right.

G: You know what I mean? Because I've got four, I've got four kids.

P: Tell me about your kids.

P: I've got a sixteen-year-old daughter. I've got a seven-year-old that's about to be eight, a five-year-old, and I've got a two-year-old.

Garrett, in his 30s, when I asked him about the kinds of work he would be willing to take: 
Prior: So what are you looking to do in the long term? What are your plans? Garrett: I'm gonna get my CDL and drive trucks state to state.

$P$ : I hear that pays quite well.

G: No problem. Benefits. Then I can [be a] fire fighter and l'd be giving back to the community more than I took and saving lives and all that ... I'll take anything [so I can] take care of my daughter. I don't need all that. I just want to live comfortably content and not paycheck to paycheck or having to worry about how I'm only gonna work three days this week and then four days next week.

In each of these cases, when asked about their economic plans, interviewees referred to their plans to work, and quickly connected those plans to their families, specifically their children, who were typically school aged, but sometimes even younger. Statements like these were often embedded within larger stories about the intent to abstain from criminal activity, i.e., desistance narratives. The experience of fatherhood for low SES men can be a turning point, a way of "making good" in the instance where they had been previously unable or unwilling to do so. The ability to be gainfully employed relates directly to interviewees conception of themselves as fathers who are able to successfully practice a provider role. Successful practicing of the provider role comes not only with material benefits, but emotional ones, which include self efficacy (Bandura, 1977), as well as better standing with the mother of the child either in the context of existing romantic relationships or as a bargaining position with the mother of the child as a co-parent who likely has legal custody over the child due to the father's incarceration. Providing economically is not the only aspect of fatherhood that is important for previously incarcerated men, but it is a salient one, which is to be expected given its status as a core feature of hegemonically masculine fatherhood. It is also the aspect of fatherhood in which low SES formerly incarcerated men are likely to be considered failing, and those failures may compromise the access that they have to their children due the frustration of the mothers of their children and the broader societal conception of them as deadbeat dads. Nevertheless, being in a position of marginalized masculinity, the formerly incarcerated viewed the hegemonically masculine provider role as a father as a motivating factor in turning away from criminal activity. Moreover, the turning point funding runs against the culture of poverty arguments that low SES black men are irresponsible or uncaring fathers.

The provider role is not the only salient issue for formerly incarcerated men. Fatherhood has changed in its conceptions over time, such that men are expected to do nurturing, caregiving, and household labor than they were not expected to do 50 years ago (Coltrane, 1997; Kaufman, 2013; Lareau, 2011). Theoretically, this seems like it could be a boon to low SES formerly incarcerated men's ability to practice fatherhood 
"Qualitative Criminology"

meaningfully-if the provider role is cut off for structural reasons, men like these could contribute meaningfully to a household by contributing more with respect to household labor and childcare while still retaining their masculine gender identity. Scholarship on black low SES non-custodial fathers has shown the importance of caregiving to be considered above that of providing economically (Edin \& Nelson, 2013; Hamer, 2001; Randles, 2020). Of course, this ignores the ways in which those tasks are socially devalued as "feminized" labor, and how the emerging new father role is more exclusive to middle class families while lower-SES fathers continue to envision fatherhood as breadwinning (Lareau, 2011). Randles in particular notes the vacuity of new fatherhood discourse in light of a lack of family friendly social policy (2020, pp. 128-132). Even so, the value of fathers being present in the lives of children has arguably taken on a new cultural salience. Unfortunately, being present is also an issue for formerly incarcerated men since they have been absent for at least some period of time due to their incarceration, albeit for varying lengths of time. Nevertheless, interviewees expressed a desire to be present in the lives of their children in spite of typically being a non-custodial parent. Take the example of Alton, who was in his late twenties and living in a halfway house. He disclosed that he had experienced juvenile incarceration for selling drugs, and for this reason had not graduated high school. When interviewed, it was his second time going through Afterward's GED classes and was currently living in a halfway house, i.e. incarcerated at night but permitted to leave to participate in Afterward's reentry programming and for work. He lamented being away from his children:

Alton: By the end of next month. It's crazy. I'm ready to go, want to go home.

Prior: I'm sure.

A: Missing all these birthdays and stuff like that. It's tough for my kids. He asks me, 'You moved out the house?' 'No, I still live there.'

$\mathrm{P}$ : They don't fully understand, the younger ones.

A: The older one, she do. She's 12. She kind of knows what is what. But Dante, he don't really pay attention to stuff like that. He don't worry about it. He has his toys, cartoons, bike. He said one day that 'Dad, you in jail?' 'I'm not in jail, I'm in school' So I gotta tell him. I don't like lie to them but I don't want them to grow up thinking that coming to jail is cool or Daddy was in jail, I'm going to go to jail. So I tell them I'm in school so they can grow up liking school. It's crazy.

$\mathrm{P}$ : Yeah, it's tough.

A: Real tough.

P: Hopefully you'll be able to get out of this place in like a month or two.

A: Yeah, hopefully. I'm doing everything l've got to do. Never had a write-up so l've never been to the hole. 
Not only is Alton worried about the consequences of being away from his children, he also specifically wants to be a role model for his son, and he is concerned that his son will repeat his behaviors after having visited him in jail. Charles reflected similarly on what it meant to him to be there for his children particularly with respect to the example that he wanted to set for them as a part of a broader desistance narrative. Charles was in his late 40s and married, but also had two children that were in the custody of their mother, a previous romantic partner. Charles had been incarcerated twice in state prison for felony drug charges, and he had most recently pled guilty to a DUI and drug possession. At the time of our interview Charles was on house arrest at his mother's house. In our interview, Charles describes an upbringing where selling drugs, i.e., "hustling" was part of what it meant to be in his family. Charles disclosed that he met his father for the first time while the two of them were incarcerated in a state prison, and his father was serving a 20 year sentence.

Charles: I started at a young age hustling with my family. One of my uncles, he was the one that put me out there to start me on this. I haven't had to try to go seek employment. I never had to work. Anything I wanted was there. I can go do what I want to do. Go to the parties, having chicks, the cars, the glamor and the glitz ... Okay, you doing this, but you hurting your own people. When are you going to give back? See I never asked myself that question before, because I never intended on giving back. Give who what? I ain't felt I owed nobody nothing. But now I recognize I owe a lot of people. Because now I see my kids coming. I don't want them to be where I've been or where I'm coming from. You understand? I want them to be where I can't go. I want them to be better than me. So they have a better life, a better chance than me. If I ain't going to be able to give them that chance, who's going to give it to them? My kids live with their mother. She's still on a negative vibe. She's still dealing with guys that's hustling. Got drugs around the children. She throws that in my face when I talk to her, because she don't recognize that I changed, so when I talk to her she says, 'Well, you used to do it. Why you getting mad at him? Because he's with me?' No, I don't care that he's with you. I'm married. I have a whole other life.

Prior: But you're worried about your kids.

C: It's not about you no more. It's not about us. It's about us trying to get along for the sake of our children, but I don't need you in my life. I need them in my life. I want them to know that their dad is there for them. See what I'm saying? Because my dad didn't have a chance to be there for me. My dad was on drugs when I was growing up. I met my dad when I was 18. When I went in jail, I met my pop. I don't want that to happen to one of my sons. 
"Qualitative Criminology"

"Struggling to Make Good":The Dilemmas of Fatherhood for Formerly Incarcerated African-American Men

After incarceration, Charles uses his fatherhood as a key part of a story about himself that shows him turning his life around. Importantly, he does not mention the provider role primarily, but rather both being present in the lives of his children and serving as a role model so that they do not repeat his mistakes. Being there as an example for his children is a key part of his desistance narrative, i.e., his resolution to not become involved in criminal activity. Still as he mentions, conflict with a previous romantic partner, the mother of his children, is a kind of barrier to being present and example setting role he wishes to play as a father.

Along the lines of being present in the lives of his children, Timothy reflected wistfully on the little time that he was able to be there for his children who were now adults with families of their own. Timothy, who was in his late 40s, explained that he had a history of robbing and stealing, which started when he was 11 years old, and had served a total of 20 years in various state prisons. Most recently he had received probation for a misdemeanor assault charge as a result of a physical altercation with his wife's exhusband. Timothy focuses on his absent fatherhood, with the possible avoidance of incarceration for his own children:

I also made a conscious decision in my life to change my life probably around 32 years old and I was in prison and I decided that this was not what I wanted for my life because l've lost a lot and over the years like seeing all the things that l've lost, my children growing up without me, not being able to be there with them when they were going through the problems that they were going through, not being able to share laughter with my daughters or, you know, taking them out to the movies, you know, or teaching them life lessons and things that they should know. I wasn't there for none of that, so it all like came to me one day and I was like, whoa, I have to change my life, I cannot keep going through this, you know ... One of the greatest things that I ever got out of life was taking my daughters to the movies, you know; several things, taking them to the movies, taking them out to dinner. At the end of the day they tell me like 'dad,' I know I felt so good ... the cycle is going to end with me. I'm going to make sure it ends with me and I'm going to do everything in my power to make sure that none of my kids or grandkids have to go to jail.

These reflections were embedded in a desistance narrative that Timothy shared about his resolution not to return to prison or jail, but also in hopes that neither his children or grandchildren would experience the same thing that he did. In this way, Timothy's hopeful role as present father or grandfather are part of the narrative he shares about avoiding incarceration for himself. 
We also heard similar concerns from Arthur who was in his mid 20s:

For the last ten years I've been in and out of jail, so I didn't really slow down and get to think that meant anything. So l'd do a year, l'd do two years, l'd come home, l'd do the same thing, so it's like, no matter what, I had to change. It's hard out here, it's not easy for you can't just get up and go get a job. And to be honest as good as the drug money was, I didn't think I didn't need, when I started realize that by selling these drugs that I'm gonna go away, I really had to make a choice I have a 10 year old son, I have a 2 year old son, and I got a 7 year old daughter, where are they gonna be if I keep disappearing in and out? I come to this program to try to figure some things out, like I said, it ain't really the direction that I really need, I basically need some guidance and some help, I'm just taking my time, it's a stressful situation coming home, you go to numerous places, they don't wanna hire you, things of that nature, where do I go from here? Do I just go back to what I know best? Or do I try something else? It's a very hard choice. There ain't no getting around it.

A number of interviewees included a discussion of their status as fathers as a part of the stories they tell about why they are motivated to cease their criminal activity and avoid returning to prison and jail. Interviewees provided different sorts of explanations within these narratives that relate to commonly held definitions of responsible fatherhood. Of course, we see interviewees who highlight the salience of the provider role. Additionally, we also see interviewees who highlight the salience of being present and role modeling for their children. Some even take this a step further by suggesting that by avoiding crime and incarceration this will lessen the likelihood that their children will engage in the same activities. Overall, interviewees' families were a part of their desistance narratives, particularly with respect to their understanding of their roles as fathers. These narratives reaffirm findings in the literature on fatherhood as a potential turning point. While the fathers were non-custodial parents, their stories demonstrate a level of concern for their children that goes against the grain of racist stereotypes of noncustodial black fathers as wholly absent or uncaring.

\section{Fatherhood and Strain Narratives}

Even as interviewees utilized fatherhood as a part of their desistance narratives, some also used fatherhood as part of how they explained criminal activity. Typically, these narratives rely on hegemonically masculine conceptions of fatherhood particularly the provider role. Desistance narratives also rely on the provider role in their explanations, but with a key difference. Discussion of fatherhood within the context of desistance narratives may look at legitimate employment as sufficient for fulfilling the provider role. 
"Qualitative Criminology"

"Struggling to Make Good":The Dilemmas of Fatherhood for Formerly Incarcerated African-American Men

In what we call "strain narratives," interviewees articulate that the legitimate employment available to them is insufficient to fulfill the provider role in hegemonically masculine fatherhood. When legitimate employment is insufficient, this creates a bind for interviewees and they turn to criminal activity as a means of providing for their family. Importantly, for formerly incarcerated black fathers in particular, there are numerous social forces outside of their control, from spatial education labor mismatch (Wilson, 1997) to low wage employer discrimination (Pager, 2009), that are relevant for understanding their ability to meet with provider conceptions of fatherhood. As noted earlier, there has been scholarship focusing on the ways that black fathers respond to "provider strain" (Bowman, 1990; Cooper et al., 2020, 2021), a great deal of which was found in the interview data. In particular, we make note of what is the "zero sum" quality of these strain narratives, even if they are articulated as something to reject in the context of a broader desistance narrative.

Take Ted as an example, who had two children. Ted was in his mid 30s and had been incarcerated three separate times in his adult life for drug and gun related convictions. Ted also disclosed that he was raised by his grandmother because his mother was an alcoholic. Recalling his experiences, he tells a story about the kind of dilemmas and pressures he faced trying to fulfill provider role expectations as a father. He discussed the difficulties of finding work, but says that he knows how to engage in income producing criminal activity that would help him make ends meet.

I don't want to go back to prison. But then you got your wife in your ear, 'baby needs this' or 'kids need this' or 'rent's due' or 'there's a light bill' and you don't have any money. What are you going to do. It's tough. Lose your family so you can stay free or jeopardize your freedom so you can keep your family for a little while.

Here Ted articulates well the kind of zero sum framing that we see with strain narratives among formerly incarcerated low SES fathers. Ted feels the pressures of the provider role of hegemonically masculine fatherhood that he does not feel he is equipped to provide without risking his own freedom. Criminal activity is the means through which Ted can provide income for his family and this activity allows him to take on the identity of a providing father.

Another interviewee Desmond voiced similar concerns to Ted. Desmond, who was in his late 20s, explained he was moving in with his girlfriend and taking care of six children, two of which were his biological children and four of which were hers from previous relationships. Desmond had dropped out of high school because he had been incarcerated just prior to graduation. When I met him, he was working on getting his GED at Afterward. He discusses the pressures he has felt as a father: 
When you got kids and a baby momma and that, something got to give. Something has to give. And you couldn't go in the house and say, 'honey, I couldn't buy groceries this month.' So you know what I did? I was out every day at the crack of dawn, asking people if they need their grass cut, if they need me to paint something for them. And I realized like this shit ain't doing it for me. I'm coming in the house with $\$ 30$ and $\$ 40$ bucks. By the time I buy a pack of cigarettes and milk, it's gone. Then I got to give her some money. It's gone. I realized I can't keep doing this. It's different on the street, man, it is. I was 17 . I'd almost seen $\$ 100,000$. So imagine going from seeing almost $\$ 100,000$ to where I'm at now. And that eats me up inside. Can't even get my kids no ice cream. I mean, that's a hurt feeling. To see the ice cream truck, you know that your kids want ice cream and you can't go get a dollar and a quarter to pay for an ice cream cone? Makes you feel less of a man.

Desmond voices his frustration with legitimate employment, illustrating how in the past he could earn a substantial amount of money from the drug trade, and now he is relegated to poverty wages. Desmond has a hegemonically masculine conception of fathers as providers-the example of not being able to buy ice cream for his children as a normally inexpensive token of his affection is wounding to his conception of himself as a father who provides for his children. Criminal activity allowed him to feel that he could provide for his children.

Nathan, in his early 40 s, voiced similar concerns about not being able to provide for his children economically without engaging in crime, even as he presents a kind of desistance narrative. Nathan had three school aged children with three different mothers. Nathan explained that he was in a special fatherhood program that was designed to facilitate compliance with child support requirements. On the one hand he expressed interest in being able to provide economically for his children and be there for them. At the same time, he criticizes himself for committing crimes that led to his incarceration but also enabled him to act in a provider role.

Nathan: I've learned that the best thing I could have done for my family was stay out of prison. But, at the time, I couldn't see that. All I could think about was how much diapers cost, how much milk cost. It was a ... I don't know what to call it. I mean, as a father your intention is to do right by your children, but, you know, sometimes we choose the wrong way to go about it. And that was basically what I, I just chose the wrong way to go about it. Now, you know, I don't go to the same places I used to go. I don't, I've totally changed what I used to do. But I find it hard to reinsert myself into this world.

Prior: What makes it hard? 
$\mathrm{N}$ : One of the things that makes it hard is temptation.

P: Okay.

$\mathrm{N}$ : You know, when things get, things get tough, my first reaction is, you know what, I could go, I could go back to what I was doing and if I do it better, I can avoid those consequences.

$P$ : I see.

$\mathrm{N}$ : That's not really true. That's not really true. You can't do bad things and expect good consequences. That just doesn't work. So now, my focus is on trying to make better decisions and stop, don't let the pressure get to me. It's a lot of pressure coming out here. Still got to provide for these kids, you know, in, in some way, shape or form. And so there's a monkey on my back all the time.

Even when Nathan is deploying a desistance narrative here, he clearly articulates the pressure he feels to provide economically, pressure that he still feels. Nathan realizes now, albeit too late, that being present in his child's life is of crucial importance having undergone a period of incarceration. While Nathan is resolved to desist from crime and be present in the lives of his children, this resolution does not solve his dilemma with respect to the economic obligations of fatherhood.

The previous narratives of strain are economic in nature, focusing on provider strain, reflecting classical strain theory (Merton, 1968). However there are other forms of strain that can lead to criminal activity (Agnew, 1992; Broidy \& Agnew, 1997). With Vincent, who is in his early thirties we have an example of recounting violent criminal activity that landed him in prison for 11 years that did not have an economic basis, but was clearly connected to an individual's role as a father figure:

Prior: You said someone had assaulted your-

Vincent: Yeah, my baby mamma, she was eight months pregnant. Her sister was fighting the boy that I had shot. So they tried to ruling it on her sister and her being pregnant, I guess she still jumped in it like trying to help get them off her sister where she shouldn't have done that because she's pregnant. So she jumped in there he had pushed her and she had fell on the ground. That's what she tells me anyway. So she called me, I react to the situation ... I go in the house, get the clothes and all that, and I make one wrong mistake, I go in the shoebox and get the gun, put it on me, go back outside, and I don't trust them in that environment that I was living in, you know, I feel more safer with that on me ... There you go. Yeah. So now we go over there, I'm supposed to go over there, I go over there now. Not forced. But I go over there just to set him up, go over there, so I wasn't standing there, my brother was talking to the boy the whole time and he was like, 'What's up with you and my little brother. Like is that situation over with? I don't 
want him to come out here and see his baby and something happens to him, this and this.' So the boy, Elijah, was ignoring him, he was ignoring him like basically telling him like we're still, like if I catch him, whatever the case may be, because he was ignoring him, so I got burnt up [angry]. They start arguing and stuff like that and I admit, I got burnt up and I pulled the gun out and I did, you know, I shot him.

Vincent's story is different from previous ones in the sense that his crime is not due to economic deprivation, but in response to physical aggression directed at the mother of his children. In hegemonic masculinity and fatherhood, being a protector is a common expectation. Vincent, while armed with a gun, takes it upon himself to confront the individual who had shoved the mother of his child to the ground. When the individual does not respond to this confrontation with due deference and respect, they get into an argument in which the situation escalates and Vincent enacts retaliatory violence out of frustration. Both the violence directed at the mother of his child and the argument itself are forms of strain to which Vincent responds with gun violence. This non-economic strain emerges out of neighborhood context and relationships that scholars have shown to facilitate violence in other instances. In particular, Anderson's (2000) work on the code of the street provides an explanation for the sequence of events as Vincent explains them in his interview. For our purposes, it is clear that what started as a performance of hegemonic masculinity's protector role veered into hypermasculine territory through the use of gun violence, which can occur when people are enacting the code of the street. This exemplifies Anderson's (2000) code of the street, where an individual engages in retaliatory violence because their honor has been besmirched rather than getting police involved (see also Collins, 2008, p. 348). The mother of Vincent's child serves as the basis of the violation of the Vincent's honor-this retaliatory violence is in response to disrespect that is connected to Vincent's conception of fatherhood.

\section{Discussion}

Our research dovetails with much of the work on low SES fathers with respect to the fact that it is difficult for them to perform fatherhood in line with the dominant standard of what this term means, particularly with respect to the provider role. In some respects, our data demonstrate the durability of hegemonic masculinity as a social and cultural force with respect to the social construction of fatherhood. The provider role aspect of hegemonically masculine fatherhood showed up in both interviewees' desistance narratives, where they resolved to avoid criminal activity and maintain wage labor employment, and their strain narratives, where they explained their previous criminal activity through a provider vision of fatherhood (Bandura, 2015; Sykes \& Matza, 1957). What is more, our research also provides a more complex vision of African American fatherhood than what has been depicted through scholarship that has promoted a culture 
"Qualitative Criminology"

of poverty lens and supports much of the scholarship that has been critical of this view. The fathers in our sample showed considerable concern about their children's well-being, desire to be with them, as well as to provide for them economically.

And yet the vision of the irresponsible African American father persists in both academia and in the public. For instance, in 2015, scholars and citizens came together to discuss the 50th anniversary of Daniel Patrick Moynihan's "The Negro Family: The Case for National Action," a document that was viewed crucial in the analysis of African American fatherhood and the question of crime and poverty. The 50th anniversary reignited a series of debates with well-read opinion writers such as The New York Times' Kristof (2015) noting that Moynihan's concern over absent African American fathers and the increase of crime and poverty in the black community had come true. This perspective is defended by luminaries within the discipline of sociology, William Julius Wilson and Robert Sampson in particular, where they insist that some of these behaviors are instrumental in reproducing poverty and crime (Greenbaum, 2015; Massey \& Sampson, 2009). The discourse on low SES black fathers has appeared in non-profit and government programs, like Obama's "my brother's keeper" initiative, that are heavily laced with "tough love" and individualistic "take responsibility" discourse, similar to low SES fatherhood programs more generally (Geary, 2017). The premise behind these initiatives is that low SES black fathers, particularly those who have experienced incarceration, are generally considered to be absent and financially negligent.

However, what is important here is the significant ways in which the interviewees discussed their relationship between fatherhood and crime. Rather than looking at criminal activity as means of creating a marginalized masculinity identity without concern for their children, these men thought about criminal activity as it relates to their role as a father. The men thought significantly about the well-being of their children. They wanted to be in their children's lives-a data point that runs counter to the stereotype of the deadbeat dad only concerned about himself. This finding relates to other scholarship that argues the dominant, culture of poverty depiction of African American fatherhood is inaccurate. For example, Eliot Liebow's sociological ethnography of low SES black men demonstrated the lack of validity of the culture of poverty arguments in Moynihan's work by demonstrating that low SES black men have the same attitudes towards difficult low wage work that the rest of society does, and do not have a distinct "anti-work" poverty subculture (Liebow, 1967). The CDC has also found that African American fathers who live with their children spend more time with them than fathers from different racial backgrounds (Jones \& Mosher, 2013). The CDC data also demonstrated that black fathers are more likely than white and Hispanic fathers to engage in a wide swath of childcare practices, such as feeding, bathing, playing and reading. And while it has been noted that $71.5 \%$ of black, non-Hispanic children are born to unmarried women, the 
majority of black fathers live with their children (59.5\%), just in unmarried households (Levs, 2015).

The work of sociologists like Phillip Cohen and economists like Heidi Hartmann have noted that while single-parent families have become more prevalent, childhood poverty and crime rates have notably dropped since the 1960s among African Americans; the same holds true for high school graduation and college completion rates of African Americans - they have almost doubled (Cohen et al., 2015). If absent African American fathers were the main driver of higher rates of poverty and poor educational outcomes, there should not be a significant reduction in crime, poverty, and dropping out of school. These structural issues and debates are important to consider in our sample of formerly incarcerated African American fathers. The fathers in our sample were separated from their children by the state via incarceration. Whether they committed crime or have decided to step away from criminal behavior, their narratives highlighted the centrality of fatherhood in a manner that demonstrated their children were their central concern. Rather than desiring to be absent from their children, these fathers wanted to be present in their children's lives. They discussed their desire to be economic providers, role models, and simply being there for them.

It is also worth discussing the notable difference between the common depiction of African American fathers in the public sphere and through their own understanding of themselves. The legacy of negative images of black fatherhood have developed a discourse where African American fathers are deemed violent, irresponsible, uncaring, dangerous and criminal prone. However, along with other scholarship that highlights the lived experience of African American men, our findings show the strong desire of formerly incarcerated African American fathers to be present in their children's lives and provide for them as well as the felt struggles of attempting both according to hegemonically masculine conceptions of fatherhood in situations of powerful economic and social constraint.

\section{Limitations}

There are limits with respect to what can be said regarding the significance of 30 interviews of formerly incarcerated low SES urban black fathers who were recruited at a workforce development oriented prisoner reentry organization. The sample is a highly specific group with a difficult set of social circumstances that may not be wholly indicative of low SES fathers more generally. Nevertheless, in sharing their desistance narratives and explanations of criminal activity, interviewees relied on definitions of fatherhood and masculinity that were readily recognizable as derived from dominant cultural constructions of these terms. To the extent that this study is an analysis of desistance 
"Qualitative Criminology"

narratives and explanations of crime, we feel that we stand on strong ground in identifying the salience of fatherhood as a key part of the way in which our interviewees shared those desistance narratives and explanations of crime. What is more difficult for us to answer is the day-to-day significance of conceptions of fatherhood for formerly incarcerated low SES urban black fathers in practice, given the nature of the current work as an interview study as opposed to an observational study. This is not a trivial matter because behaviors may be much different than viewpoints, particularly when the behaviors in question, i.e., parenting, require substantial dedication of time and resources.

\section{Implications}

Among formerly incarcerated urban black fathers who shared their stories with us, their status as fathers was a crucial way in which they framed their own behaviors and commitments. These stories run counter to stereotyped versions of urban low SES black fathers as uninterested in their children or beholden to a culture of poverty. On the one hand, they frequently used fatherhood as part of their desistance narratives, in which they resolved to "make good" and avoid committing crime again. In doing so they relied on hegemonically masculine conceptions of fatherhood, specifically that they would aim to participate in the formal workforce in order to provide for their children. In their desistance narratives they also highlighted the importance of being present in their child's lives in ways that to some extent derive from discourses of new fatherhood. In the context of a desistance narrative, we found that economic provider roles and being there roles were not in conflict with each other.

The same could not be said for fatherhood when discussed by interviewees in the context of explanations of previous criminal activity, which we call strain narratives. In these explanations, interviewees often highlighted the extent to which the demands of these two roles were in conflict, and therefore produced zero sum dilemmas for them. Either engage in criminal activity to fulfill the provider role while risking incarceration, or be present while failing to meet with the demands of the provider role while likely working in a thankless and demanding low wage dead-end job. This dilemma is particularly indicative of concepts of strain and marginalized masculinity. Even in contexts where interviewees recognized that risking incarceration was ultimately self-defeating, they still embedded these strain explanations in larger desistance narratives to convey emotional injury at the felt dilemmas of marginalized fatherhood and masculinity.

Like other interview studies of low SES non-custodial fathers, our study is likely of interest to quantitatively oriented criminologists for a few reasons. One reason, as noted by several scholars in this area, is that low SES non-custodial fathers are often comparatively difficult to access in large datasets or in studies of low SES families more 
generally (Edin \& Nelson, 2013; Hamer, 2001; Waller, 2002). Quantitative criminologists may also be interested in the kinds of reasoning and processes that interview data offer that underlie what often lie behind dichotomous variables, e.g., custodial vs non-custodial, as the literature tends to illustrate that it is unusual for non-custodial fathers to be fully absent from the lives of their children. Given that most incarcerated men have children, understanding the reasoning of system-involved men with respect to their children is likely to be of interest to quantitative criminologists as well.

At the center of our data is the significance of the provider role for formerly incarcerated black fathers. It is established that stable formal employment is a good way of not only avoiding recidivism (Uggen, 2000), such that it is intuitive that stable formal employment would help with the provider role. However, it is also established that there are numerous structural barriers to this occurring that cannot be so easily overcome through targeted social policy (Pager, 2009; Wilson, 2010). Additionally targeted reentry policy efforts can become disciplinary and exploitative in themselves as they are a reflection of low wage labor market conditions (Prior, 2020, 2021). Suffice to say, there is something to be said for broad structural change that would render the social contract tolerable for the working poor in society, e.g., increasing the minimum wage to a living wage of $\$ 25$ an hour, as the working poor is the larger group whom formerly incarcerated black men are a part of, such that they would benefit. With respect to criminal justice policy, aside from making sentencing less punitive and policing less invasive across the board, we concur with Wacquant's recommendations that reentry policies be reinvigorated, e.g., furloughs and commutations to maintain fathers connections with children, as well as the elimination of collateral consequences for incarceration re: prohibitions on public housing, welfare support, and educational grants, and regulation of the "rap sheet" industry which has now gone digital (Lageson, 2016; Wacquant, 2009). All of these would help create the material conditions that could facilitate the assumption of the provider role identity for formerly incarcerated fathers.

Our findings and arguments regarding the salience of the father identity for formerly incarcerated black men build on previous work in qualitative criminology that has focused on this area by emphasizing the specific constructions of masculinity that are relevant for understanding the significance of fatherhood in stories of both crime and social reintegration. As others have mentioned (Black \& Keyes, 2020; Curtis, 2019; Edin et al., 2004; Jones, 2018; Lewis \& Hong, 2020; McKay et al., 2019), fatherhood as both a role and identity is a core feature of the reintegrative process for formerly incarcerated men. For low SES urban black men in particular, it is a role that they assume against a political backdrop of blame for numerous social problems stemming from their presumed absence as fathers, while simultaneously constrained in their ability to remain involved in the lives of their families via mass incarceration's disproportionate impact upon them. 


\section{References}

Agnew, R. (1992). Foundation for a general strain theory of crime and delinquency. Criminology, 30(1), 47-88.

Anderson, E. (1992). Streetwise: Race, class, and change in an urban community. University Of Chicago Press.

Anderson, E. (2000). Code of the street: Decency, violence, and the moral life of the inner city (Reprint). W. W. Norton \& Company.

Bandura, A. (1977). Self-efficacy: Toward a unifying theory of behavioral change. Psychological Review, 84(2), 191-215.

Bandura, A. (2015). Moral disengagement: How people do harm and live with themselves (First Edition edition). Worth Publishers.

Black, T., \& Keyes, S. (2020). It's a setup: Fathering from the social and economic margins (1st edition). Oxford University Press.

Blauner, B. (2001). Still the big news: Racial oppression in America (Rev Exp). Temple University Press.

Bowman, P. J. (1990). Coping with provider role strain: Adaptive cultural resources among black husband-fathers. Journal of Black Psychology, 16(2), 1-21.

Broidy, L., \& Agnew, R. (1997). Gender and crime: A general strain theory perspective. Journal of Research in Crime and Delinquency, 34(3), 275-306.

Burgess-Proctor, A. (2006). Intersections of race, class, gender, and crime: Future directions for Feminist Criminology. Feminist Criminology, 1(1), 27-47.

Chambers, D. L. (1979). Making fathers pay: The enforcement of child support (Illustrated edition). University of Chicago Press.

Charmaz, K. (2014). Constructing grounded theory (2 edition). SAGE Publications Ltd. Chesney-Lind, M. (2006). Patriarchy, crime, and justice: Feminist criminology in an era of backlash. Feminist Criminology, 1(1), 6-26. 
Francis Prior and Steven Farough

Coates, T.-N. (2014, June). The case for reparations. The Atlantic. https://www.theatlantic.com/magazine/archive/2014/06/the-case-for-

reparations/361631/

Cohen, P., Hartmann, H., Hayes, J., \& Childers, C. (2015, March 5). Moynihan's half century: Have we gone to hell in a hand basket? Council on Contemporary Families. https://contemporaryfamilies.org/moynihan-half-century-brief-report/

Coley, R. L. (2001). (In)visible men. Emerging research on low-income, unmarried, and minority fathers. The American Psychologist, 56(9), 743-753.

Collins, P. H. (2005). Black sexual politics: African Americans, gender, and the new racism (1st edition). Routledge.

Collins, P. H. (2008). Black feminist thought: Knowledge, consciousness, and the politics of empowerment (1st ed.). Routledge.

Collins, R. (2008). Violence: A micro-sociological theory. Princeton University Press.

Coltrane, S. (1997). Family man: Fatherhood, housework, and gender equity (1st edition). Oxford University Press.

Connell, R. W. (1987). Gender and power: Society, the person, and sexual politics (1st edition). Stanford University Press.

Connell, R. W. (2005). Masculinities (Second edition). University of California Press.

Connell, R. W., \& Messerschmidt, J. W. (2005). Hegemonic masculinity: rethinking the concept. Gender \& Society, 19(6), 829-859.

Cooper, S. M., Robbins, P. A., Burnett, M., McBride, M., Shaheed, J., \& Smith, N. A. (2020). African American fathers' coping patterns: Implications for father-son involvement and race-related discussions. Journal of Applied Developmental Psychology, 70, 101163.

Cooper, S. M., Smith, N. A., Burnett, M., McBride, M., \& Supple, A. (2021). Stereotype awareness and black fathers' paternal engagement: At the nexus of racial and fathering identities. Psychology of Men \& Masculinities, 22(3), 443-454.

Curtis, A. (2019). Dangerous masculinity: Fatherhood, race, and security inside America's prisons. Rutgers University Press. 
"Qualitative Criminology"

Dyer, W. J. (2005). Prison, fathers, and identity: A theory of how incarceration affects men's paternal identity. https://doi.org/10.3149/FTH.0303.201

Edin, K., \& Nelson, T. J. (2013). Doing the best I can: Fatherhood in the inner city. University of California Press.

Edin, K., Nelson, T. J., \& Paranal, R. (2004). Fatherhood and incarceration as potential turning points in the criminal careers of unskilled men. In M. Pattillo, D. F. Weiman, \& B. Western (Eds.), Imprisoning America: The Social Effects of Mass Incarceration. Russell Sage Foundation.

Fader, J. J., \& Traylor, L. L. (2015). Dealing with difference in desistance theory: The promise of intersectionality for new avenues of inquiry. Sociology Compass, 9(4), 247260.

Furstenberg, F. F. (2007). The making of the black family: Race and class in qualitative studies in the twentieth century. Annual Review of Sociology, 33(1), 429-448.

Geary, D. (2017). Beyond civil rights: The Moynihan Report and its legacy (Reprint edition). University of Pennsylvania Press.

Gibson, M. A., \& Ogbu, J. U. (1991). Minority status and schooling: A comparative study of immigrant and involuntary minorities. Garland.

Giordano, P. C., Cernkovich, S. A., \& Rudolph, J. L. (2002). Gender, crime, and desistance: Toward a theory of cognitive transformation. American Journal of Sociology, 107(4), 990-1064.

Greenbaum, S. D. (2015). Blaming the poor: The long shadow of the Moynihan Report on cruel images about poverty. Rutgers University Press.

Griffith, D. M., \& Cornish, E. K. (2018). "What defines a man?": Perspectives of African American men on the components and consequences of manhood. Psychology of Men \& Masculinity, 19(1), 78-88.

Hamer, J. F. (2001). What it means to be daddy. Columbia University Press.

Haney, L. (2018). Incarcerated fatherhood: The entanglements of child support debt and mass imprisonment. American Journal of Sociology, 124(1), 1-48. 
Holzer, H. (2009). Collateral Costs: Effects of Incarceration on Employment and Earnings Among Young Workers. In S. Raphael \& M. A. Stoll (Eds.), Do prisons make us safer?: The benefits and costs of the prison boom (Illustrated edition). Russell Sage Foundation.

Hooks, B. (2003). We real cool: Black men and masculinity (1st edition). Routledge.

Jarrett, R. L., Roy, K. M., \& Burton, L. M. (2002). Fathers in the "hood": Insights from qualitative research on low-income African-American men. In Handbook of Father Involvement. Routledge.

Jones. (2018). The chosen ones: Black men and the politics of redemption. University of California Press.

Jones, J., \& Mosher, W. D. (2013). Father's Involvement With Their Children: United States 2006-2010 (No. 71; National Health Statistics Reports). Centers for Disease Control.

Kaufman, G. (2013). Superdads: how fathers balance work and family in the 21st century. NYU Press.

Kimmel, M. (2011). Manhood in America: A cultural history (3rd edition). Oxford University Press.

Kristof, N. (2015, March 12). Opinion | When liberals blew it. The New York Times. https://www.nytimes.com/2015/03/12/opinion/when-liberals-blew-it.html

Labor, O. of P. P. and R. U. S. D. of. (1981). The negro family: The case for national action (New edition). Greenwood Press Reprint.

Lageson, S. E. (2016). Found out and opting out: The consequences of online criminal records for families. The ANNALS of the American Academy of Political and Social Science, 665(1), 127-141.

Lareau, A. (2011). Unequal childhoods: Class, race, and family life, second edition with an update a decade later (2nd ed.). University of California Press.

Levs, J. (2015). All In: how Our work-first culture fails dads, families, and businesses-and how we can fix it together. HarperOne. 
"Qualitative Criminology"

Lewis, D., \& Hong, P. Y. P. (2020). Incapacitated fatherhood: The impact of ass incarceration on black father identity. Journal of Qualitative Criminal Justice \& Criminology.

Lewis, Jr., Garfinkel, I., \& Gao, Q. (2007). Incarceration and unwed fathers in Fragile Families. Journal of Sociology \& Social Welfare, 34(3), 77-94.

Lewis, O. (1975). Five families: Mexican case studies in the culture of poverty. Basic Books.

Liebow, E. (1967). Tally's corner: A study of negro streetcorner men (2nd ed.). Rowman \& Littlefield Publishers.

Majors, R., \& Billson, J. M. (1993). Cool pose: The dilemmas of black manhood in America (Reprint edition). Touchstone.

Maruna, S. (2001). Making good: How ex-convicts reform \& rebuild their lives. American Psychological Association (APA).

Massey, D., \& Denton, N. (1993). American apartheid: Segregation and the making of the underclass. Harvard University Press.

Massey, D. S., \& Sampson, R. J. (2009). Moynihan redux: Legacies and lessons. The ANNALS of the American Academy of Political and Social Science, 621(1), 6-27.

McDougal III, S. (2020). Black men's studies: Black manhood and masculinities in the U.S. Context (New edition). Peter Lang Publishing.

McKay, T., Comfort, M., Lindquist, C., \& Anupa, B. (2019). Holding on: Family and fatherhood during incarceration and reentry. University of California Press.

Mead, L. M. (1993). The new politics of poverty: The nonworking poor in America (Reprint edition). Basic Books.

Merton, R. (1968). Social structure and anomie. In Social Theory and Social Structure (pp. 185-215). The Free Press.

Messerschmidt, J. W. (2018). Masculinities and crime: A quarter century of theory and research (25th Anniversary edition). Rowman \& Littlefield Publishers. 
Miller, J. (1998). Up it up: Gender and the accomplishment of street robbery*. Criminology, 36(1), 37-66.

Mincy, R. B., Jethwani, M., \& Klempin, S. (2014). Failing our fathers: Confronting the crisis of economically vulnerable nonresident fathers. Oxford University Press.

Neal, M. A. (2015). New black man: Tenth anniversary edition (2nd edition). Routledge.

Nelson, T. J. (2004). Low-income fathers. Annual Review of Sociology, 30(1), 427-451.

Pager, D. (2009). Marked: Race, crime, and finding work in an era of mass incarceration (Reprint). University of Chicago Press.

Potter, H. (2015). Intersectionality and criminology: Disrupting and revolutionizing studies of crime. Routledge.

Prior, F. B. (2020). Security culture: Surveillance and responsibilization in a prisoner reentry organization. Journal of Contemporary Ethnography, 49(3), 0891241620908651. https://doi.org/10.1177/0891241620908651

Prior, F. B. (2021). Urban neoliberal debt peonage: Prisoner reentry, work, and the new Jim Crow. Social Currents, 2329496521991578. https://doi.org/10.1177/2329496521991578

Quillian, L. (2012). Segregation and poverty concentration: The role of three segregations. American Sociological Review, 77(3), 354-379.

Rainwater, L. (1967). And the poor get children. Quadrangle.

Randles, D. J. M. (2020). Essential dads: The inequalities and politics of fathering. University of California Press.

Randles, J. (2020). Role modeling responsibility: The essential father discourse in responsible fatherhood programming and policy. Social Problems, 67(1), 96-112.

Roy, K. (1999). Low-income single fathers in an African American community and the requirements of welfare reform. Journal of Family Issues, 20(4), 432-457.

Roy, K. M. (2006). Father stories: A life course examination of paternal identity among low-income African American men. Journal of Family Issues, 27(1), 31-54. 
Roy, K. M., \& Dyson, O. (2010). Making daddies into fathers: Community-based fatherhood programs and the construction of masculinities for low-income African American men. American Journal of Community Psychology, 45(1-2), 139-154.

Ryan, W. (1976). Blaming the victim (2nd ed.). Vintage.

Sampson, R. J. (1987). Urban black violence: The effect of male joblessness and family disruption. American Journal of Sociology, 93(2), 348.

Smiley, C. (2019). Release in the rra of BLM: The nexus of Black Lives Matter and prisoner reentry. The Prison Journal, 99(4), 396-419.

Stack, C. B. (1997). All our kin: Strategies for survival in a black community. Basic Books.

Stuart, F., \& Benezra, A. (2018). Criminalized masculinities: How policing shapes the construction of gender and sexuality in poor black communities. Social Problems, 65(2), 174-190.

Sykes, G. M., \& Matza, D. (1957). Techniques of neutralization: A theory of delinquency. American Sociological Review, 22(6), 664-670.

Uggen, C. (2000). Work as a turning point in the life course of criminals: A duration model of age, employment, and recidivism. American Sociological Review, 65(4), 529-546.

Venkatesh, S. A. (2009). Off the books: The underground economy of the urban poor. Harvard University Press.

Wacquant, L. (2009). Punishing the poor: The neoliberal government of social insecurity. Duke University Press Books.

Waller, M. (2002). My baby's father: Unmarried parents and paternal responsibility. Cornell University Press.

West, C., \& Zimmerman, D. H. (1987). Doing gender. Gender \& Society, 1(2), 125-151.

Western, B. (2002). The impact of incarceration on wage mobility and inequality. American Sociological Review, 67(4), 526-546.

Western, B. (2018). Homeward: Life in the year after prison. Russell Sage Foundation. 
Williams, J. M. (2019). Race as a carceral terrain: Black Lives Matter meets reentry. The Prison Journal, 99(4), 387-395.

Williams, J. M., Wilson, S. K., \& Bergeson, C. (2019). "It's hard out here if you're a black felon": A critical examination of black male reentry. The Prison Journal, 99(4), 437-458.

Wilson, W. J. (1990). The truly disadvantaged: The inner city, the underclass, and public policy. University Of Chicago Press.

Wilson, W. J. (1997). When work disappears: The world of the new urban poor. Vintage.

Wilson, W. J. (2010). More than just race: Being black and poor in the inner city. W. W. Norton \& Company.

\section{Contributors}

Francis Prior is an Assistant Professor of Sociology and Criminology at Assumption University. He received his PhD in Sociology from the University of Pennsylvania. His research interests include prisoner reentry, urban ethnography, the sociology of race, class, and gender, and social movements.

Steven Farough is an Associate Professor of Sociology at Assumption University. He received his PhD in Sociology from Boston College. His research interests include stayat-home fathers, masculinities, whiteness, and the sociology of race, class, and gender.

\section{Acknowledgement}

Special thanks to David Grazian for acting as the dissertation committee chair for the research for which this was conducted. Thanks to John MacDonald and Dorothy Roberts for also serving as committee members for the dissertation on which this research was conducted. Thanks go to John Halushka for providing a thorough review of an earlier draft of the manuscript and providing several useful reference points in the literature on fatherhood and incarceration. Thanks to Blake R Silver for organizing the Family and Inequality Roundtable at the Annual Meeting of the ASA for which this paper was accepted. Thanks to the editors and peer reviewers at The Journal of Qualitative Criminal Justice and Criminology for their helpful feedback and guidance throughout this process; the paper is stronger for their contributions. We are excited to publish at this forwardthinking open access journal. A special thanks to the formerly incarcerated fathers who participated in this study in spite of particularly difficult life circumstances, and by whom we are humbled. 